\title{
Identifying and preparing the next generation of part-time clinical teachers from dental practice
}

\author{
IN BRIEF \\ - Explains the role of a part-time clinical \\ teacher. \\ - Offers an opinion on how this resource \\ needs to be nurtured and developed. \\ - Offers an insight into many of our general \\ dental practitioner and dental care \\ professional colleagues' aspirations to \\ contribute to undergraduate education.
}

\author{
D. R. Radford, ${ }^{* 1}$ P. Hellyer, ${ }^{2}$ N. Meakin ${ }^{2}$ and K. A. Jones ${ }^{2}$
}

Part-time general dental practitioners (GDPs) and dental care professionals (DCPs) working in practice are being increasingly utilised to deliver undergraduate clinical dental education to both dental and hygiene/therapy students. As such, there is a need for appropriate recruitment processes and ongoing staff development in the different and complex role of the clinical teacher. Recently a group of experienced dental practitioners, making a journey from GDP to part-time clinical teacher, identified common themes, experiences, challenges and realisations. These were: 'what is clinical dental education?'; 'me as a clinical teacher'; and 'specific teaching issues'. The themes highlighted the complexity of dental education and the different environment of the teaching clinic from general practice. Some of the themes identified could be a starting point for the induction process to facilitate an easier transition from experienced GDP to clinical teacher. With the current demands from both students and patients alike, the 'three way dynamic of patient, student and teacher' needs to be supported if dental schools are to attract and develop the highest quality clinical teachers. It is of critical importance to give an exceptional experience to students in their clinical education as well as to patients in terms of excellent and appropriate treatment. The challenge for deans and directors of education is to find the resources to properly fund teacher recruitment, induction and the development of part-time GDPs in order to produce the expert teachers of tomorrow.

\section{INTRODUCTION}

Part-time GDPs and DCPs in practice are being increasingly utilised to deliver undergraduate clinical dental education to both dental and hygiene therapy students. Furthermore, when established, they are often involved with initial selection of new members of the profession, year examinations such as OSCEs (observed structured clinical examinations) and examining case presentations for finals. As such, effective recruitment and a planned approach to development, in the different and complex role of the clinical teacher are essential. Correctly, this significant responsibility for clinical teaching is even greater in outreach education, where a rich mix of experienced primary care clinicians from a variety of NHS, independent practice and community services provide more senior students with a balanced view of clinical dentistry. ${ }^{1}$ At the

\footnotetext{
'Senior Lecturer Hon Consultant, Integrated Dental Education and Multi-Professional Care, Kings College London Dental Institute; ${ }^{2}$ Clinical Teacher, Kings College London Dental Institute and University of Portsmouth Dental Academy, Faculty of Science, William Beatty Building, Portsmouth, P01 20G

${ }^{*}$ Correspondence to: David R. Radford

Email: david.radford@kcl.ac.uk
}

\section{Refereed Paper}

Accepted 18 September 2015

DOI: $10.1038 /$ sj.bdj.2015.748

${ }^{\circledR}$ British Dental Journal 2015; 219: 319-322
University of Portsmouth Dental Academy (UPDA) over $90 \%$ of all clinical teaching to dental students is delivered by part-time GDPs.

In the last 18 months two papers investigating part-time clinical teachers' motivation to undertake teaching roles in dental schools and their career progression have been published in this journal., ${ }^{2,3}$ The paper from Davis et $a .^{2}$ reported on the clinical teachers in the primary care department of King's College London Dental Institute (KCLDI) and concluded that part-time clinical teachers have a strong influence on the issues of the modern clinical curriculum and are certainly valued as a vital resource. The second paper from Bristol Dental School used the same questionnaire devised by Davis et al., ${ }^{2}$ but their target group was all the part-time dental clinical teachers within the school, thus giving insight to those teaching restorative and paediatric dentistry, orthodontics and oral surgery as well as teachers delivering outreach education. They concluded that there were insufficient and unequal opportunities for career progression and development within their institution. ${ }^{3}$

\section{VOCATION}

Both papers reported that the teachers were certainly experienced practitioners (Bristol, mean number of years post qualification was 24 years; and at KCLDI the part-time teachers had a mean of 18.5 years post qualification experience) and a number of staff had gained teaching qualifications either at certificate or diploma level. Their motivation to contribute to the teaching was the same in both papers, namely that of 'vocation'. However, the limited opportunities for career progression were discussed. ${ }^{2,3}$ We are sure that the motivation of 'vocation' as a career aspiration is highly attractive to many of our colleagues. This notion was captured by Kay and 0'Brien ${ }^{4}$ in their thought provoking opinion paper in which succession planning in academic dentistry was discussed, stating "to know that your skills you have garnered in your own clinical experience will be passed on to other generations, and will benefit countless patients, is a supreme joy. ${ }^{4}$

\section{RECRUITMENT PROCESS FOR PART-TIME CLINICAL TEACHERS}

Just as it has been accepted that clinical academics have to undergo a very rigorous selection process to assess their aptitude for their chosen career (as well as gain teaching qualifications to make them aware of some of their weaknesses as teachers and to develop those areas), we would argue that it is important to consider the recruitment 
process for part-time clinical teachers in order to educate future generations of the dental team to the highest standards. Further, we would argue that it is essential for parttime clinical teachers to embark upon appropriate induction and training, ideally before they are given full responsibility for young people within our profession who are in their most impressionable and formative years. Personal experience suggests that currently, a clinician's aptitude for chairside teaching is explored at best at interview where questions such as 'what teaching experience have you had?' are asked. The replies may range from teaching their nurse, through to some limited involvement of nursing education at the local further education college, to experience as a dental foundation trainer. Candidates at interview may be given a scenario to talk through, for example, "how would you handle a queue of four students when one of your other students is having difficulty with an extraction on a nervous patient?' or 'a second year hygiene/therapy student who is struggling with the placement of a matrix band and is running late for his next patient'. Some schools and departments who deliver face to face postgraduate programmes may be in the fortunate position to be able to identify clinicians who are potentially good teachers first hand and this has always been a hidden added value of those programmes to their dental school. We most certainly do not decry these experiences or interview panels' attempts to identify potentially good teachers. However, when the complexity of dental education is studied in depth, it is evident that more needs to be invested in the identification of potential superlative parttime clinical teachers and their subsequent initial training and support as new clinical teachers.

\section{TRANSITION FROM EXPERIENCED GENERAL DENTAL PRACTICTIONER TO NOVICE TEACHER}

A recent auto-ethnographic study explored the experiences of three highly experienced practitioners making that exact transition through novice to experienced clinical teachers. ${ }^{5}$ It explored some of the interactions, complexity and the frustrations, as well as the rewards of the role. The thematic analysis identified three major themes (Table 1).

We accept that inspirational teachers do not necessarily need teaching qualifications, but would strongly argue that, as we should all aspire to be that 'inspirational teacher' some formal training and mentoring is necessary. ${ }^{6-8}$ For example, in a recent article in the Times Higher Education, it was reported that lecturers with formal teaching qualifications are valued far more highly by

\section{Table 1 Thematic analysis of issues raised by novice clinical teachers}

\begin{tabular}{l|l}
\hline Main themes & Sub themes \\
$\begin{array}{l}\text { What is clinical dental education? } \\
\text { (what does it involve?) }\end{array}$ & $\begin{array}{l}\text { The complexity of dental education } \\
\text { Skills and knowledge of a new dentist } \\
\text { Interacting with agencies (internal and external) } \\
\text { Outreach experience and environment (specific for their role in teaching } \\
\text { in an outreach setting) }\end{array}$ \\
\hline Me as a 'clinical teacher' & $\begin{array}{l}\text { Me teaching 'professional practice' } \\
\text { Me teaching 'clinical skills' } \\
\text { 'What I do, day in, day out' } \\
\text { Understanding oneself as a 'clinical teacher' }\end{array}$ \\
\hline $\begin{array}{l}\text { Specific teaching issues and } \\
\text { coping strategies }\end{array}$ & $\begin{array}{l}\text { The dynamic of the three parties in clinical education 'the three way dynamic' } \\
\text { The importance of feedback and how to deliver it } \\
\text { The juggling of time and numbers of students }\end{array}$ \\
\hline
\end{tabular}

Reproduced from Radford D R, Hellyer P, Jones K A, Meakin N. J Interdiscip/ Med Dent Sci 2014; 2: 147 (Ref. 5)

Table 2 Perceptions of chairside teachers and what they bring to the clinical situation

\begin{tabular}{|l|l}
\hline Dental practitioners & $\begin{array}{l}\text { Knowledge of dentistry } \\
\text { Wide clinical experience }\end{array}$ \\
\hline Senior academics & $\begin{array}{l}\text { Knowledge of dentistry } \\
\text { Wide clinical experience } \\
\text { Additional subject specificity }\end{array}$ \\
\hline Intuitive teacher practitioners & $\begin{array}{l}\text { Knowledge of dentistry } \\
\text { Critically appraised clinical experience } \\
\text { Intuitive good teaching ability }\end{array}$ \\
\hline Teacher trained academic & $\begin{array}{l}\text { Knowledge of dentistry } \\
\text { Wide clinical experience } \\
\text { Knowledge of processes of education }\end{array}$ \\
\hline Dental educational developers & $\begin{array}{l}\text { Knowledge of dentistry } \\
\text { Wide clinical experience } \\
\text { Knowledge of processes of education } \\
\text { Critical appraisal of teaching and systems }\end{array}$ \\
\hline Reproduced from Sweet J, Pugsley L, Wilson J. Br Dent $J$ 2008; 205: 565-569 (Ref. 8)
\end{tabular}

students than those who are active researchers. In vocational subjects, students sought those with professional expertise. ${ }^{9}$ A rich mix of experienced colleagues from practice has been utilised at UPDA which suits the learning styles of a diverse group of dental, hygiene/therapy and dental nursing student colleagues within the integrated team approach to education. ${ }^{1}$ Further, although all clinicians have been in the student corner 'of the dynamic of the three parties in clinical education, ${ }^{5}$ some formal teaching and mentorship of being in the teacher's corner would be of clear benefit to the novice teacher.

The three highly experienced practitioners also discussed their development as teachers, referring to the work of Sweet et $a l^{8}{ }^{8}$ who recognised five types of clinical teacher (Table 2). The category 'dental practitioners,' view 'their position as one who helps students by example and as role models'. However, the novice teachers aspired to become intuitive teacher practitioners (Table 2) and in the study it came through strongly that the novice teachers recognised that they had embarked upon a new journey: ${ }^{5}$
'What I now have is a far greater understanding of the processes of teaching and learning'.

'What I also know is that now overlaid over my 'networks of understanding' of dentistry, I now have the beginning - and it is only a beginning - of another network, that of the educational process itself'.

'As my confidence and learning has developed I feel I have been able to participate in progressive teaching that has enabled my personal philosophy as a teacher to be fulfilled:

The work of Schon ${ }^{10}$ applied learning and development in higher education, particularly to medicine and nursing education. The key assumptions and nature of reflective practice can be closely applied to aspiring dental educators. We provide educational experiences that allow the student to question, develop a scientific and self-critical approach to their dental care, and nurture this for their future progression and development. This approach to the education of our students was again reflected by the novice teachers: ${ }^{5}$ 
Table 3 Skills that need to be mastered by dentists

\begin{tabular}{l|l}
\hline 1 & Remembering a large amount of factual information \\
\hline 2 & Understanding complex mechanisms \\
\hline 3 & Competence in a range of technical skills \\
\hline 4 & Understanding and use of the scientific method \\
\hline 5 & Developing professionalism, socially responsible attitudes and ethical practice \\
\hline 6 & Deploying interpersonal skills for working with colleagues and patients \\
\hline 7 & Developing sophisticated problem-solving and diagnostic reasoning skills \\
\hline 8 & Personal skills, including self-evaluation and reflective practice \\
\hline $\begin{array}{l}\text { Reproduced from Fry H, Ketteridge } S, \text { Marshall S. A handbook for teaching and learning in higher education. 2nd ed. Oxford: } \\
\text { Routledge, 2009: } 425 \text { (Ref. 14) }\end{array}$
\end{tabular}

'I realised that the role of the clinical teacher is complex. On reflection, I now understand that it is more than just supervision alone, but about encouraging and guiding the student to reflect on their own practice':

'I would define my learning ability as that of the "reflective observer" and, instead of trying to fight against my learning style, I now 'go with the flow' and try to operate within understood parameters. This has, as a consequence, enabled me to be far more empathetic and effective when assisting students to learn within their individual comfort zones and/or gently push them into their "zone of proximal development".'11

'As clinical teachers, with our own commitment to lifelong learning, feedback must be a reciprocal process because we too continuously learn from our students' experiences, either via the students themselves, their patients, carers and/or other members of the multi-disciplinary team?

The development of our student colleagues is critical, so we would argue that it is incumbent on our profession to provide training and support, not just for full time academic teachers, ${ }^{4}$ but also for part-time clinical teachers who provide much of the clinical teaching and who contribute to a highly knowledgeable and skilled work force in dental education. Just as individual dentists will have spent time, money and energy in developing clinical, chairside, management and finance skills, those that wish to teach need to develop the skills of an expert teacher. As clinicians we have had a skills progression that has been classified into five stages: Novice - Advanced beginner - Competent - Proficient - Expert. ${ }^{12}$ As teachers we need to progress through the same stages. GDPs will have become unconsciously competent ${ }^{13}$ in the skills itemised in Table 3 (adapted from Fry et al. ${ }^{14}$ ), but a different skill set is needed as a clinical educator to unpack them and apply them to patient and student management in a busy and often stressful teaching clinic.

\section{SUPPORT FOR THE NOVICE TEACHER}

The identified themes and subthemes are of interest to current and aspiring clinical teachers as they relate to teaching in dental schools and outreach settings. Initial teacher education of both full and part-time teachers could be based around the themes identified. ${ }^{5}$ This would support new clinical teachers in 'finding their feet' in an often unfamiliar environment where, unlike their normal general practice, they are in charge of the actions of several students simultaneously with regards to delivery of care. The student clinic is a challenging environment and some new clinical tutors may feel isolated. Most recently, developmental guidelines for good chairside teaching have been published. ${ }^{15}$ In this paper the authors recognised many of the factors that were discussed by the novice teachers and they explicitly outlined the challenges faced by clinical teachers at the chairside. The authors aimed to provide a universal toolkit for improved chairside teaching which will enhance the students' learning experience. ${ }^{15}$ By adopting some of the suggested proposals, both from this opinion paper and that of Wilson et al., ${ }^{15}$ an increasingly effective clinical education should be facilitated, thus providing our student colleagues with optimal individual learning experiences that will allow them to reach their full potential. ${ }^{5,16}$

It is clear that the experienced GDPs quoted, recognised that teaching clinical dentistry is a highly complex and demanding role. ${ }^{5}$ Directors of Teaching and Clinical Deans in dental schools need to ensure that new staff are properly supported in terms of access to high quality clinical teacher educational fora, as well as an induction period of a reduced supervisory role. This will allow observation of other teachers to encourage the novice teacher to develop good practice and to develop their own style, thus playing to their strengths. The goodwill of existing teachers can be tapped into, as in our experience, teachers love teaching anyone and are happy to share their knowledge and practise. Resource has to be found to first identify and recruit the potentially inspirational part-time clinical GDPs and DCPs, second to mentor them and third, to provide time to allow this development to occur. The difficulty that this poses is that the delivery of the clinical programme is a full 46 week year. The logistics of training part-time clinical teachers is challenging as often they are asked to attend sessions on some of their non-teaching days, and although this can be compensated for with time in lieu, a consequence of this is that those teaching sessions then have to be covered. Part-time teachers also, by definition, have other fixed commitments and to attend on a different day may present considerable logistic challenges to them.

At the UPDA, we have had experience of a generic initial training programme offered to all University of Portsmouth lecturers and of one that was provided by King's College London Learning Institute (KLI). Although both courses were of value, the KLI course, as it had a significant number of part-time teachers from the caring professions, was deemed the more valuable by those who attended, due to the shared experiences of the participants. The majority of part-time clinical teachers do not deliver formal lectures, but importantly their clinical seminars import some of the very welcome informality of the 'dental practice team meeting' to the university learning environment. Additionally, there is an opportunity to meet individual student's learning needs through the clinical seminar and one to one teaching in the clinical environment. A deeper understanding of the different ways in which students learn, provided by teacher training, adds considerably to the richness and benefit of these opportunities. As clinical teachers we do not always know what the student takes away from these encounters and elements that we might dismiss as unimportant, may contribute to the most salient learning points for that individual student. Again, the "three way dynamic of patient, student and teacher ${ }^{25}$ needs to be supported if the profession is to attract, develop and retain the highest quality clinical teachers who are able to give an exceptional experience and clinical education to our students.

\section{CONCLUSION}

The area of part-time clinical teacher development is under researched and if we are to discontinue the old mantra of 
the 1980s and 90s of 'see one - do one and then teach one', this whole process of identification, the transition from experienced clinical practitioner, through to novice teacher and then experienced clinical teacher and finally, intuitive practitioner/ teacher, needs to be further researched. Support, albeit through a reducing unit of resource for dental education, is also required throughout the lifelong journey of the part-time clinical teacher if we are to capitalise on the valuable experience they bring to the education of our student colleagues. If we are to continue to give our student colleagues an exceptional experience while at dental school, the teaching role of part-time clinical teachers needs as much recognition and resource as the succession planning of clinical academics and the research output of our British university dental schools. Realistically, the only way to provide effective teacher education to part-time clinical teachers is to exceed the current staff to student ratio (SSR), and aspire to provide staff levels above that SSR to allow peer review, peer mentorship and teacher development.
Acknowledgements

The authors would like to thank Professor Mark Woolford, King's College London and Mrs Leanna Wynne, University of Portsmouth, for their constructive contributions to the manuscript.

1. Radford D R. A personal perspective, breaking new ground in Portsmouth in integrated dental education and professional care. Higher Education Research Network Journal 2011; 2: 67-71. Available online at http://www.kcl.ac.uk/study/ learningteaching/kli/research/hern/hern-j2/DavidRadford-hernjvol2.pdf (accessed September 2015).

2. Davies B R, Leung A N, Dunne S M. Why do general dental practitioners become involved in clinical teaching? A pilot study exploring the views of parttime practitioner teachers, King's College London. Br Dent J 2013; 214: 461-456.

3. Puryer J, McNally L, O'Sullivan D. The views of parttime teachers regarding their role in undergraduate education at the University of Bristol Dental School. Br Dent J 2015; 218: 79-83.

4. Kay E J, O'Brien K D. Academic dentistry-where is everybody? Br Dent J 2006 200: 73-74.

5. Radford D R, Hellyer P, Jones K A, Meakin N. Experienced general dental practitioners as clinical teachers: A qualitative study of their experience over the first three years as novice clinical teachers in an outreach setting. J Interdiscip/ Med Dent Sci 2014; 2: 147. Available online at http://www.omicsonline. com/open-access/experienced-general-dentalpractitioners-as-clinical-teachers-jimds-2-147. php?aid=32137 (accessed September 2015).

6. Carrote PV. Educating the educators - do university lecturers require training in educational practice? $\mathrm{Br}$ Dent J 1994; 177: 217-220.
7. Sweet J, Pugsley L, Wilson J. Stakeholder perceptions of chairside teaching and learning in one UK dental school. Br Dent J 2008; 205: 499-503.

8. Sweet J, Pugsley L, Wilson J. Chairside teaching and the perceptions of dental teachers in the UK. Br Dent J 2008; 205: 565-569.

9. Grove J. Student survey rates teaching qualification above research activity. Times Higher Education 2015. Available online at https://www. timeshighereducation.co.uk/content/studentsurvey-rates-teaching-qualifications-aboveresearch-activity. (accessed September 2015).

10. Schon D. Educating the reflective practitioner. San Francisco: Jossey Bass, 1987.

11. Vygotsky L. Social development theory. LearningTheories.com, 2012. Available online at http://www. learning-theories.com/vygotskys-social-learningtheory.html (accessed September 2015).

12. Kinchin I, Cabot L B, Hay D. Visualising expertise: towards an authentic pedagogy for higher education. Teach Higher Edu 2008; 13: 315-326.

13. Gordon T. Learning a new skill is easier said than done. Gordon Training International, (2011). Available online at http://www.gordontraining.com/ free-workplace-articles/learning-a-new-skill-iseasier-said-than-done/ (accessed September 2015).

14. Fry H, Ketteridge $\mathrm{S}$, Marshall S. A handbook for teaching and learning in higher education. 2nd ed. Oxford: Routledge, 2009.

15. Wilson J, Sweet J, Pugsley L. Developmental guidelines for good chairside teaching-a consensus report from two conferences. Eur J Dent. Educ 2015; 19: 185-191.

16. Radford D R, Hellyer P. Final year dental students' and other stakeholders' perceptions of their experience at a residential outreach centre. Br Dent J 2015; 219: 171-175. 